\title{
Risks Of Organization's Value Chain
}

\author{
Jerzy Zemke, University of Gdańsk, Poland
}

\begin{abstract}
An organization's management specifies planned value of the chain of activities. The outcome is affected by unpredictable, random factors, the source of which can be found both in the organization's environment and inside it. The effect of this influence can be positive or negative which means that the chain value may be higher or lower than planned. This is a result of the effect of activities-related risks on added value generated in the organization's functional areas.
\end{abstract}

\section{INTRODUCTION}

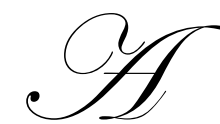

investment.

n organization's strategic plan determines those activities of management that assume achievement of goals set in the plan. The strategic policy allows for activities of management intended to open the opportunities of generating a financial outcome that guarantees a high rate of return on

The expected rate of return on investment should assume competitive advantage over other products of the financial market. The organization's financial outcome is determined by added value which results from processing the organization's resources into products or services, followed by selling them on the market for some specified value. The difference between the value of resources consumed for production and the value of sales constitutes added value ${ }^{1}$.

An organizational strategy assumes added value maximization ${ }^{2}$. This situation results from the fact that management undertakes coordinated activities in all functional areas of the organization. The effectiveness of these activities is reflected by added value generated in each functional area. The cumulated outcome of activities defines value of the organization's chain. Thus, added value is equal to the total of values resulting from activities undertaken by the organization's management in all its functional areas.

An organization's management specifies planned value of the chain of activities. The outcome is affected by unpredictable, random factors, the source of which can be found both in the organization's environment and inside it. The effect of this influence can be positive or negative which means that the chain value may be higher or lower than planned. This is a result of the effect of activities-related risks on added value generated in the organization's functional areas.

To implement the organizational strategy, it is required to undertake the activities outlined in plans, and management's activities also include those relating to the chain's value protection from consequences of risks of activities. It is possible for management to satisfy the expectations on the condition that convincing evidence is formulated to support the thesis that risks can be identified and measured.

The assumption that the risk model is a random vector identifies the risk space, defines the procedure of risk identification, and identifies measures of this risk. Is this really so? Does the identity of a risk model with the

\footnotetext{
* Basic Value Chain

${ }^{1}$ Definition of added value: generated by a concrete enterprise, this is a value which is added to the value of products and services and which represents a difference between their costs and the price at which they are sold. This value consists of net profit, corporate income tax, depreciation, interest on loans and credit, and salaries with surcharges. Rokita J., Zarządzanie Strategiczne. Tworzenie i utrzymanie przewagi konkurencyjnej. PWE Warszawa 2005, p. 185.

${ }^{2}$ The rule of added value maximization results from the superiority of shareholders' interests. If added value does not achieve the level of their expectations, capital withdrawal occurs.
} 
random vector really define the risk identification procedure? According to the definition, random vector is a systematic set of coordinates - random components; therefore, in order to identify risk, it is enough to define vector components. Is this possible? This can be proven based on the theoretical foundation; so how does a solution like this function in practice of the organization management's activities? The answer to this question is expected to come from risk analysis of the organization's basic chain of activities.

\section{RISK MEASUREMENT}

The identity of the business organization management processes, along with the risk management processes, can be accepted as a fundamental axiom of the management theory ${ }^{3}$. Its reliability is supported by the essence of management processes, which should be perceived as processes of planning, implementing the plans and controlling the compliance of execution. Together with the contents of these plans, both in risk management theory and in practice, the quality of management processes should enable achievement of the organization's planned goals; i.e. it is exactly the same as what we expect when managing the organization.

The management's activities cannot be random in nature; they occur in the functional areas of the organization's structure that have been identified. Therefore, they can be named. And what is more, it is possible to identify the characteristics of these activities. Specific risks relate to these activities. If one accepts the hypothesis that characteristics of named risks are random variables, it is possible to define a set of specific relations between the characteristics - the risk profile. As components can take any numerical value, the risk profile is a random vector $\boldsymbol{X}^{i}=R^{i}\left(X_{1}^{i}, X_{2}^{i}, \ldots, X_{k}^{i}\right)$ with the probability density function $f^{i}\left(x_{1}^{i}, x_{2}^{i}, \ldots, x_{k}^{i}\right)$ and $p^{i}\left(x_{1}^{i}, x_{2}^{i}, \ldots, x_{k}^{i}\right)$ and with the following function of probability distribution:

$$
P\left\{X_{1}^{i}=x_{1_{l}}^{i}, X_{2}^{i}=x_{2_{l}}^{i}, \ldots, X_{k}^{i}=x_{k_{l}}^{i}\right\}=p\left(x_{1_{l}}^{i}, x_{2_{l}}^{i}, \ldots, x_{k_{l}}^{i}\right)
$$

where: $x_{1}^{i} \in\left[a_{1}^{i}, b_{1}^{i}\right], \ldots, x_{k}^{i} \in\left[a_{k}^{i}, b_{k}^{i}\right], R^{i}-\operatorname{risk}(i=1,2, \ldots, n), X_{j}^{i}$ - risk characteristics $(j=1,2, \ldots k)$.

Besides identifying named risks, it is similarly important to assume the distribution of the random vector probability density function - a multidimensional random variable $R^{i}$. What we expect here is not only an answer to the question about how many times an event occurs, but we are also asking about the informational contents concerning distribution of the variable probability density function, which is why we are directing our choice toward continuous random distributions ${ }^{4}$. A significant compliance is forecasted by empirical distributions of $R^{i}$ relation with a lognormal distribution ${ }^{5}$.

$$
\begin{gathered}
f\left(x_{1}, \ldots, x_{k}\right)=\frac{1}{\prod_{i=1}^{k} x_{i}(2 \pi)^{\frac{k}{2}} \sqrt{|M|}} \exp \left\{\frac{-1}{2} \sum_{g=1}^{k} \sum_{h=1}^{k} \gamma_{g h}\left(\ln x_{g}-\mu_{g}\right)\left(\ln x_{h}-\mu_{h}\right)\right\} \text {, where: } \\
M=\left(\begin{array}{cccc}
\sigma_{1}^{2} & \eta_{12} & \ldots & \eta_{1 k} \\
\eta_{21} & \sigma_{2}^{2} & \ldots & \eta_{2 k} \\
\cdot & . & . & \cdot \\
\eta_{k 1} & \eta_{k 2} & \ldots & \sigma_{k}^{2}
\end{array}\right), \sigma_{i}^{2} \text { stands for variance of } X_{l} / l=1,2, \ldots, k / \text { random variable and } \eta_{g h}
\end{gathered}
$$

\footnotetext{
${ }^{3}$ Zemke J., Zarządzanie ryzykiem a zarządzanie organizacja, Zeszyty Naukowe issue no 3, Business and Administration College, Gdynia 2006.

${ }^{4}$ In this case, the continuous random variable value is usually represented not by the number telling us how many times an event occurs, but by a more general measure of quantitative properties of some random events, Pawłowski Z. Wstęp do statystyki matematycznej p. 129 - 186, PWN Warszawa 1969.

${ }^{5}$ Similar properties can be observed with gamma distribution, Pawłowski Z. op. cit. p. 176 - 183. Properties of distribution are discussed by Aitchison J., Brown J.A.C., The Lognormal Distribution, Cambridge 1957.
} 
for covariance of $\left\{X_{g}, X_{h}\right\}$ variables, while $\gamma_{g h}$ represent elements of $M^{-1}$ matrix.

Certainly, the compliance of named risks distribution probability density function, with the lognormal distribution, is a challenge that requires practical knowledge of solving multiple definite integrals. If one accepts a hypothesis like this, it is possible to estimate: ${ }^{6}$

- the probability of event that components $\left\{X_{j}^{i}\right\}$ of the random vector take values from a certain range $\left[a_{j}^{i}, b_{j}^{i}\right]$,

- random vector expected /average/ value,

- random vector variance,

- covariance of $\left\{X_{g}^{i}, X_{h}^{i}\right\}$ variables,

- random vector boundary components.

The possibility of determining the risk profile measures referred to is a natural consequence of risk identification, its random nature and the possibility of quantifying the risk characteristics. It seems obvious how one should select tools for measuring changes in risk profile for a risk defined in this way. The solution can be found as a result of an attempt to define new measurement tools or by means of referring to those that have already been defined. If they exist and are sufficiently effective and efficient, they should be used for this purpose.

Mathematical statistics provide adequate tools enabling one to determine changes in random vector position in the vector space precisely. They occur as a result of changes of the risk profile components. ${ }^{7}$

Definition 1: The probability of events that random variables $\left\{X_{j}^{i}\right\}$ take values $x_{j}^{i}$ from the range $\left[a_{j}^{i}, b_{j}^{i}\right]$, equals:

$$
P\left(a_{1}^{i} \leq X_{1}^{i} \leq b_{1}^{i}, \ldots, a_{k}^{i} \leq X_{k}^{i} \leq b_{k}^{i}\right)=\int_{a_{1}^{i}}^{b_{1}^{i}} \ldots \int_{a_{k}^{i}}^{b_{k}^{i}} f^{i}\left(x_{1}^{i}, \ldots, x_{k}^{i}\right) d x_{1}^{i} . . d x_{k}^{i} .
$$

Definition 2: Random vector expected magnitude:

$$
E\left(X^{i}\right)=\left(E\left(X_{1}^{i}\right), E\left(X_{2}^{i}\right), \ldots, E\left(X_{k}^{i}\right)\right)^{8},
$$

where : $E\left(X_{l}^{i}\right)=\int_{a_{l}^{i}}^{b_{l}^{i}} x_{l}^{i} f^{i}\left(x_{1}^{i}, \ldots, x_{k}^{i}\right) d x_{l}^{i}, \quad l=1,2, \ldots, k$.

Definition 3: Random variable $\left\{X_{j}^{i}\right\}$ variance equals:

$$
\operatorname{Var}\left(X_{l}^{i}\right)=\int_{a_{l}^{i}}^{b_{l}^{i}}\left[x_{l}^{i}-E\left(X_{l}^{i}\right)\right]^{2} f^{i}\left(x_{1}^{i}, x_{2}^{i}, \ldots, x_{k}^{i}\right) d x_{l}^{i}, \quad l=1,2, . ., k .
$$

Definition 4: Random variables $\left\{X_{g}^{i}, X_{h}^{i}\right\}$, where $X_{g}^{i}=x_{g}^{i} \wedge x_{g}^{i} \in\left[a_{g}^{i}, b_{g}^{i}\right], X_{h}^{i}=x_{h}^{i} \quad x_{h}^{i} \in\left[a_{h}^{i}, b_{h}^{i}\right]$, covariance equals:

\footnotetext{
${ }^{6}$ Hypothetical measures of continuous distribution are definite integrals in a multidimensional space. In empirical studies, numeric methods are used for solving multiple integrals.

${ }^{7}$ Change in the position of a random vector in the vector space is identical with the risk level change resulting from changing risk profile measures.

${ }^{8}$ Multidimensional random variable expected value is a vector with components $E\left(X_{j}^{i}\right)$.
} 


$$
\operatorname{Cov}\left(X_{g}^{i}, X_{h}^{i}\right)=\int_{a_{g}^{i}}^{b_{g}^{i} g_{h}^{i}} \int_{h}^{i}\left[x_{g}^{i}-E\left(X_{g}^{i}\right)\right]\left[x_{h}^{i}-E\left(X_{h}^{i}\right)\right] f^{i}\left(x_{1}^{i}, x_{2}^{i}, \ldots, x_{k}^{i}\right) d x_{g}^{i} d x_{h}^{i}, g, h=1,2, . ., k \wedge g \neq h
$$

Definition 5: If $R^{i}\left(X_{1}^{i}, X_{2}^{i}, \ldots, X_{k}^{i}\right)$ relation is continuous, the function of density of $R^{i}$ risk profile conditional distribution probability against $\left\{X_{j}^{i}\right\}$ random variable, on the condition $X_{j}^{i}=x$ equals:

$$
P\left\{\left(a_{1}^{i}<x_{1}^{i} \leq b_{1}^{i} \ldots, a_{j-1}^{i}<x_{j-1}^{i} \leq b_{j-1}^{i}, a_{j+1}^{i}<x_{j+1}^{i} \leq b_{j+1}^{i}, \ldots, a_{k}^{i}<x_{k}^{i} \leq b_{k}^{i}\right) \mid\left(X_{j}^{i}=x\right)\right\}=H,
$$

where:

$$
H=\int_{a_{1}^{i}}^{b_{1}^{i}} \ldots \int_{a_{j-1}^{i}}^{b_{j-1}^{i}} \int_{j+1}^{b_{j+1}^{i}} \ldots \int_{a_{k}^{i}}^{b_{k}^{i}} \frac{f^{i}\left(x_{1}^{i}, x_{2}^{i}, \ldots, x_{k}^{i}\right)}{f^{i}\left(x_{j}^{i}\right)} d x_{1}^{i} \ldots d x_{j-1}^{i} d x_{j+1}^{i} \ldots d x_{k}^{i}, j=1,2, \ldots, k
$$

Definition 5.1: The conditional expected value of $R^{i}$ risk profile - on the condition that $X_{j}^{i}=x$ - is a vector: $E$ $\left(R^{i} \mid X_{j}^{i}=x\right)=\left(E\left(X_{1}^{i} \mid\left(X_{j}^{i}=x\right)\right), \ldots E\left(X_{j-1}^{i} \mid\left(X_{j}^{i}=x\right)\right), \ldots, E\left(X_{k}^{i} \mid\left(X_{j}^{i}=x\right)\right)\right)$, where

$$
E\left(X_{l}^{i} \mid\left(X_{j}^{i}=x\right)\right)=\int_{a_{j}^{i}}^{b_{j}^{i}} x_{l}^{i} \frac{f^{i}\left(x_{1}^{i}, x_{2}^{i}, \ldots, x_{k}^{i}\right)}{f^{i}\left(x_{j}^{i}\right)} d x_{l}^{i} ; l=1,2, \ldots, k \wedge \quad l \neq j .
$$

Definition 5.2: Conditional variances of $\left\{X_{l}^{i}\right\}$ characteristics - on the condition that $X_{j}^{i}=x$ - equal:

$$
\operatorname{Var}\left(X_{l}^{i} \mid\left(X_{j}^{i}=x\right)\right)=\int_{a_{l}^{i}}^{b_{l}^{i}}\left[x_{l}^{i}-E\left(X_{l}^{i} \mid X_{j}^{i}=x\right)\right]^{2} f^{i}\left(x_{1}^{i}, x_{2}^{i}, \ldots, x_{k}^{i}\right) d x_{l}^{i}, \text { where } l=1, \ldots, k \wedge l \neq j .
$$

Definition 5.3: Conditional covariances of $\left\{X_{g}^{i}, X_{h}^{i}\right\}$ characteristics and of $I$ - th profile of $R^{i}$ risk - on the condition that $X_{j}^{i}=x$ - equal:

$$
\operatorname{Cov}\left(\left(X_{g}^{i}, X_{h}^{i}\right) \mid\left(X_{j}^{i}=x\right)\right)=\int_{a_{g}^{i}}^{b_{g}^{i} b_{h}^{i}}\left[x_{g}^{i}-E\left(X_{g}^{i} \mid\left(X_{j}^{i}=x\right)\right)\right]\left[x_{h}^{i}-E\left(X_{h}^{i} \mid\left(X_{j}^{i}=x\right)\right)\right] f^{i}\left(x_{1}^{i}, x_{2}^{i}, \ldots, x_{k}^{i}\right) d x_{g}^{i} d x_{h}^{i},
$$

where: $g, h=1, \ldots, k \wedge(g \neq h, g \neq j, h \neq j)$.

\section{RISKS OF ORGANIZATION'S VALUE CHAIN}

Although the concept of an organization's value chain is a matter of convention in practice of management's activity, it enables one to identify the activities of the management precisely, and it also systematizes them, defining sets of activities performed by the management in the organization's functional areas.

This formal relation systematizing activities of management systematizes risks of activities at the same time, as formally this process reflects the order established in the set of activities. These formal divisions and arrangements, although one might regard them as insignificant, perfectly throw light on the matter of analysis. Assigning activities to functional areas enables one to name the activities and consequently; it identifies the value chain risks.

The organization's value chain, in principle - a set of basic activities and supporting activities - is a source of two separate sets of risks: basic chain and support chain risks. Both value chains are sets of activities of 
management that concern direct relations within departments and between departments; but on the other hand, they are undertaken with the subjects from the organization's environment as well. Risks of activities undertaken by management will be internal, relating to activities in the basic chain and the support chain, but they are also risks of activities resulting from necessary relations with the organization's surroundings.

\subsection{Basic Chain Risks}

Basic chain risks make themselves visible in activities of such departments as logistics and purchasing, production, marketing, sales, and servicing. Consequences of risks can adversely affect the outcome of management's activities, but this effect can be positive as well. This is the Anglo-Saxon approach to risk. In both cases, management will strive for identifying risks of activities, first of all being aware of negative effects of risks.

\subsubsection{Risks of Logistics and Procurement}

The thesis that the organization's value chain is a systematic set has an unquestionable substantiation. Both logistics and purchasing represent the first link in the value chain. Activities of management include purchasing of raw materials, materials, energy, machines and devices, technologies and also include logistics, where the organization undertakes activities intended to transfer the purchased items to their target location defined in the production process. Logistic activities can be limited to the organization's own means of transport or they can be performed by specialized shipping companies. In some cases, activities of the management can coordinate the external shipping company's work with that of an organization's own transport.

The context of activities of management guaranteeing the production continuity is made complete by activities defining the size, frequency of orders, and the moment when the order is renewed, i.e. by the organization's inventory management.

The outcome of the analysis of management activities, according to the area they apply to, is the organization's environment. This differentiation matters in terms of risks of activities in the area of procurement and logistics since it answers questions about selecting adequate and effective risk management tools ${ }^{9}$.

The efficiency of activities in the area of procurement and logistics depends on quality of the set of assumptions and rules that constitute a basis for activities of management. The organization's purchasing department determines the range, quality, quantity and size of delivery batches, the frequency of deliveries, packing requirements, protection of goods during transportation, shipping documents, rules of inspecting deliveries in terms of product range, quality and quantity, rules of financing deliveries, and means of compensation if terms of delivery are not observed.

Even if terms and rules of delivery are defined in a clear manner, these arrangements do not always guarantee that activities of management are effective and efficient because they can be affected by the lack of reliability in relations with suppliers and shipping companies.

The logistics and procurement risk profile defines many characteristics, and most of them - cost, product range, quality, packaging, product protection in transportation - are not measurable. Although measurable, characteristics of the profile give orientation in the dynamics of risk changes, but similarly, as non-measurable characteristics referred to above, they do not translate into categories of financial, technical or technological characteristics. Loss of production processes smoothness is a consequence of logistics and procurement risks and therefore cannot be the risk profile characteristics.

\footnotetext{
${ }^{9}$ It is more effective to control results of activities undertaken by the organization's management than to control activities concerning subjects that operate in the organization's surroundings. In case of identified risks of activities where cooperation with external entities is involved - technical problems relating to monitoring effects of activities - one should use products that guarantee that effects of risks are transferred to risk carriers. This solution, although expensive, is effective.
} 


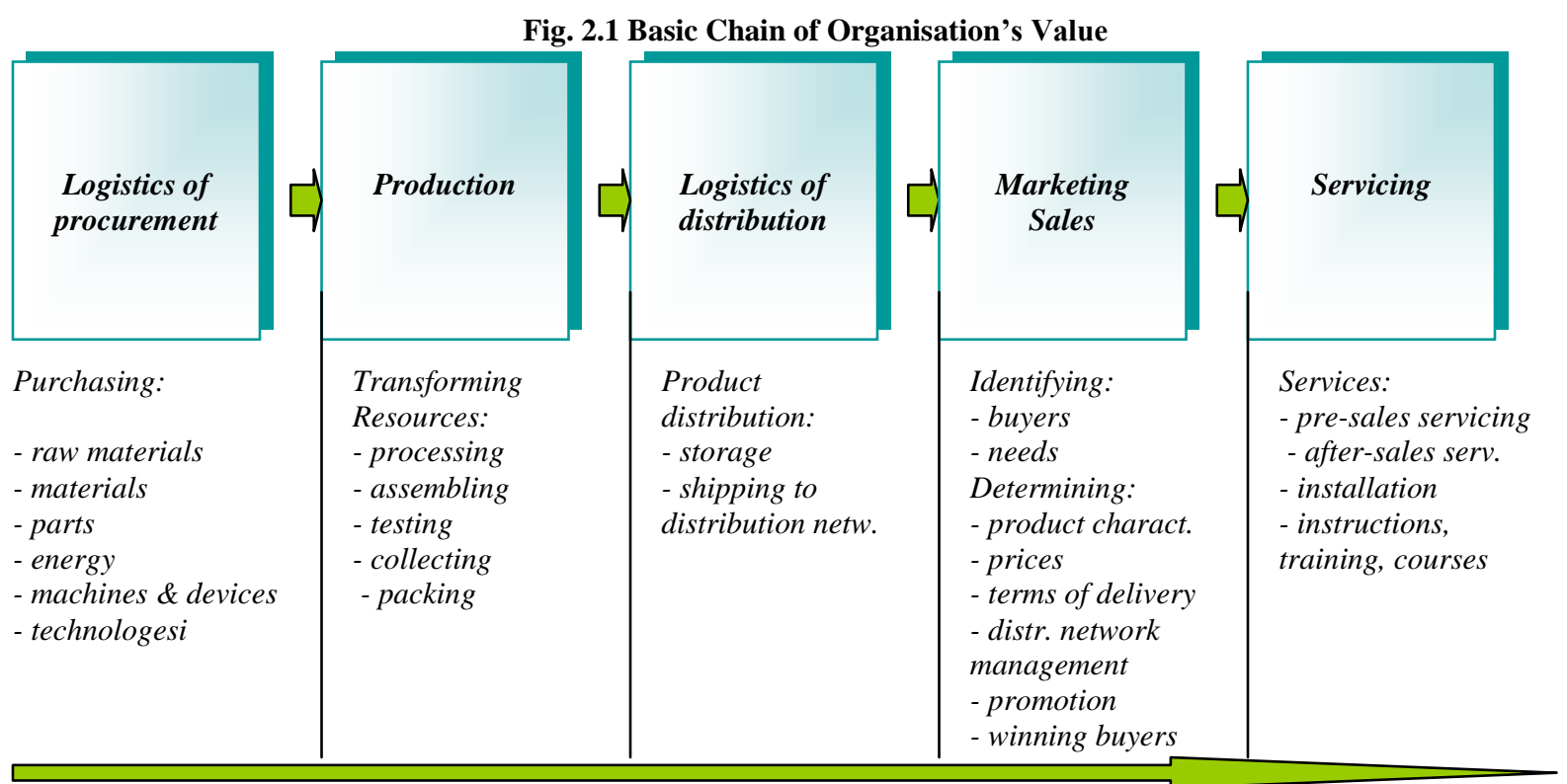

Source: based on Rokita J. (2005) Gotębiowski T (2001)

A well organized process of procurement uses a schedule of deliveries: specific quantities of ordered items $(Z I)$ to be delivered at some specific point of time $(M C)$. Determining the real size of the executed order $\left(Z I^{(r)}\right)$ and the real time of delivery $\left(M C^{(r)}\right.$ ), we are defining two characteristics of the risk profile: $\Delta Z I$ measures the variance between the planned and received size of delivery and $\triangle M C$ measures the variance between the planned and actual time of delivery.

The capability of measuring characteristics $\Delta Z I$ and $\triangle M C$ is certainly a considerable approximation of the organization's risk in a situation when values of both characteristics of the profile exceed the acceptable level, as they may result in a break in the production process continuity. To solve this problem should rather fall under the competence of the risk management system. One might think that the continuous process of changes in $\Delta Z I$ and $\triangle M C$ characteristics, in combination with the possibility of replenishing the resources to the necessary minimum or procuring suitable means of transport, combines activities of monitoring changes in the risk profile and activities limiting effects of logistics and procurement risks.

Assuming that activities of management preclude any shortage or delays in supply, the process of deliveries can be interrupted as a result of demands - justifiable or not - to change the price, if the supplier or the shipping company is the organization's only partner or when changes of prices result from conspiracy on the market. Effects of such demands change the costs of production $(\Delta K P)$, therefore worsening the organization's competitive edge.

Thus, the logistics and procurement risk profile is a random vector with Tyree random variables

$$
X_{L i Z}=(\Delta Z I, \Delta M C, \Delta K P) .
$$

Let $X_{1} \equiv \Delta Z I, \quad X_{2} \equiv \Delta M C, \quad X_{3} \equiv \Delta K P$ and let the function of probability distribution density be lognormal, with the assumption that random variables $X_{j}=x_{j}$ for $j=1,2,3$, take values from some closed interval of variability $\left[a_{j}, b_{j}\right] \subset R^{+}$, then: 
a. Function of probability distribution density:

$$
f\left(x_{1}, x_{2}, x_{3}\right)=\frac{1}{(2 \pi)^{\frac{3}{2}} * \sqrt{|M|} * \prod_{l=1}^{3} x_{l}} \exp \left\{-\frac{1}{2} \sum_{g=1}^{3} \sum_{h=1}^{3} \gamma_{g h}\left(\ln x_{g}-\mu_{g}\right)\left(\ln x_{h}-\mu_{h}\right)\right\},
$$

where: $M=\left(\begin{array}{ccc}\sigma_{1}^{2} & \eta_{12} & \eta_{13} \\ \eta_{21} & \sigma_{2}^{2} & \eta_{23} \\ \eta_{31} & \eta_{32} & \sigma_{3}^{2}\end{array}\right), \sigma_{i}^{2}$ stands for variance of $X_{j}$ random variable and $\eta_{g h}$ for

covariance of $\left\{X_{g}, X_{h}\right\}$ variables, while $\gamma_{g h}$ represent elements of matrix $M^{-1}, g, h=1,2,3$.

b. Probability of events that random variables $X_{j}$ take values $x_{j}$ from the range:

$$
P\left(a_{1} \leq x_{1} \leq b_{1}, a_{2} \leq x_{2} \leq b_{2}, a_{3} \leq x_{3} \leq b_{3}\right)=\int_{a_{1}}^{b_{1}} \int_{a_{2}}^{b_{2} b_{3}} f\left(x_{3}, x_{2}, x_{3}\right) d x_{1} d x_{2} d x_{3} .
$$

c. Expected value of the logistics and procurement risk profile $E(X)=\left(E\left(X_{1}\right), E\left(X_{2}\right), E\left(X_{3}\right)\right)$, where components of vector equal respectively: $E\left(X_{l}\right)=\int_{a_{l}}^{b_{l}} x_{l} f\left(x_{1}, x_{2}, x_{3}\right) d x_{l}$, where $l=1,2,3$.

d. Variances of characteristics of the logistics and procurement risk profile $\left\{X_{j}\right\}$, equal:

$$
\operatorname{Var}\left(X_{l}\right)=\int_{a_{l}}^{b_{l}}\left[x_{l}-E\left(X_{l}\right)\right]^{2} f\left(x_{1}, x_{2}, x_{3}\right) d x_{l}, \text { where } l=1,2,3 .
$$

e. Covariances of characteristics of the logistics and procurement risk profile $\left\{X_{g}, X_{h}\right\}$, equal:

$$
\operatorname{Cov}\left(X_{g}, X_{h}\right)=\int_{a_{g}}^{b_{g} b_{h}} \int_{h}\left[x_{g}-E\left(X_{g}\right)\right]\left[x_{h}-E\left(X_{h}\right)\right] f\left(x_{1}, x_{2}, x_{3}\right) d x_{g} d x_{h}, g, h=1,2,3 \wedge g \neq h .
$$

f. Assuming that for any component $\left\{X_{j}\right\}$, where $j=1,2,3$, the variable takes constant value $X_{j}=x$, while $\left\{X_{g}, X_{h}\right\}$ variables can take values form the $\left[a_{g}, b_{g}\right] \times\left[a_{h}, b_{h}\right] \subset R^{2}$, where $g, h=1,2,3 \wedge g \neq h \wedge g \neq j \wedge h \neq j$, the function of conditional probability distribution density equals by definition:

$$
P\left(a_{g} \leq x_{g} \leq b_{g}, a_{h} \leq x_{h} \leq b_{h} \mid X_{j}=x\right)=\int_{a_{g}}^{b_{g}} \int_{h} \frac{f\left(x_{1}, x_{2}, x_{3}\right)}{f\left(x_{j}\right)} d x_{g} d x_{h},
$$

$\mathrm{f}_{1}$. Conditional expected value of the logistics and procurement risk profile is a random vector, if one of the profile components is constant $X_{j}=x$, while the remaining variables $\left\{X_{g}, X_{h}\right\}$ can take values from the $\left[a_{g}, b_{g}\right] \times\left[a_{h}, b_{h}\right] \subset R^{2}$, where $g, h=1,2,3 \wedge g \neq h \wedge g \neq j \wedge h \neq j$ equals by definition:

$$
E\left(E\left(X_{g} \mid X_{j}=x\right), E\left(X_{h} \mid X_{j}=x\right)\right), \quad E\left(X_{l} \mid X_{j}=x\right)=\int_{a_{l}}^{b_{l}} x_{l} \frac{f\left(x_{1}, x_{2}, x_{3}\right)}{f\left(x_{j}\right)} d x_{l},
$$

where: $l=1,2,3 \wedge l \neq j$. 
$\mathrm{f}_{2}$. If one of components of the profile $X_{j}=x$ takes constant value, Chile the remaining characteristics $\left\{X_{l}\right\}$ may take any value from the range $\left[a_{l}, b_{l}\right] \subset R^{+}$, where $l=1,2,3 \wedge l \neq j$, conditional variance of characteristics of the logistics and procurement risk profile equals by definition:

$$
\operatorname{Var}\left(X_{l} \mid X_{j}=x\right)=\int_{a_{l}}^{b_{l}}\left[x_{l}-E\left(X_{l} \mid X_{j}=x\right)\right]^{2} f\left(x_{1}, x_{2}, x_{3}\right) d x_{l} .
$$

$\mathrm{f}_{3}$. Conditional covariance of characteristics $\left\{X_{g}, X_{h}\right\}$ of the procurement logistics risk profile - on the condition that $X_{j}=x, \quad\left\{X_{g}, X_{h}\right\}$ can take values from the $\left[a_{g}, b_{g}\right] \times\left[a_{h}, b_{h}\right] \subset R^{2}$, where $g, h=1,2,3 \wedge$ $g \neq h \wedge g \neq j \wedge h \neq j$ - equal:

$\operatorname{Cov}\left(\left(X_{g}, X_{h}\right) \mid\left(X_{j}=x\right)\right)=\int_{a_{g}}^{b_{g} b_{h}}\left[x_{h}-E\left(X_{g} \mid\left(X_{j}=x\right)\right)\right]\left[x_{h}-E\left(X_{h} \mid\left(X_{j}=x\right)\right)\right] f\left(x_{1}, x_{2}, x_{3}\right) d x_{g} d x_{h}$

\subsubsection{Production Risks}

Production processes transform resources; i.e. they include processing, assembling, testing, collecting, and they end with packing. Resources are transformed as a result of human resources' interaction and processing materials and raw materials with the use of technologies and technical support.

The role of human resources, irrespective of the degree of production process automation, is essential; and considering the fact that behaviors are significantly less predictable, ignoring the potential effect of human resources management risks is an obvious mistake. It is difficult to measure characteristics of the human resources management risk profile, as changes of characteristics result from the monitoring person's subjective assessment. The problem of measuring risk profile characteristics can be solved by replacing them all with one characteristic that defines changes in production costs: $\triangle K P$.

Implications of activities performed by management in the area of human resources always emerge in changes of production costs, similarly as effects of procurement and logistics risks or technological risks. Changes in production costs is a symptomatic characteristic as the direct relation between production costs and activities relating to transformation of resources necessary in the production process - particularly in the sphere of human resources management - is difficult to quantify. The relation results from accepting a hypothesis that undesirable effects of activities of the management will cause additional costs. The risk profile is defined as a random vector $\boldsymbol{X}_{p r}=(\Delta K P)$.

Let $X^{p r} \equiv \triangle K P$ and let the function of probability distribution density be lognormal, with the assumption that random variables $X^{p r}=x^{p r}$ take value from a certain closed interval of variability $[a, b] \subset R^{+}$, then:

a. Probability distribution density function:

$$
f(x)=\frac{1}{x \sigma \sqrt{2 \pi}} \exp \left\{-\frac{(\ln x-\mu)^{2}}{2 \sigma^{2}}\right.
$$

where: $\sigma^{2}$ stands for $X$ random variable variance and $\mu$ for $X$ variable average value.

b. $\quad$ Probability of events that random variable $X^{p r}=\ln X$ takes value $x^{p r}=\ln x$ from $[a, b] \subset R^{+}$equals:

$$
P(a \leq x \leq b)=\int_{a}^{b} \frac{1}{x \sigma \sqrt{2 \pi}} \exp \left\{-\frac{(\ln x-\mu)^{2}}{2 \sigma^{2}} d x .\right.
$$


c. Production risk profile expected value: $E(X)=\frac{1}{\sigma \sqrt{2 \pi}} \int_{a}^{b} \exp \left\{-\frac{(\ln x-\mu)^{2}}{2 \sigma^{2}} d x\right.$.

d. Production risk profile variance:

$$
\operatorname{Var}(X)=\int_{a}^{b}[x-E(X)]^{2} \frac{1}{x \sigma \sqrt{2 \pi}} \exp \left\{-\frac{(\ln x-\mu)^{2}}{2 \sigma^{2}} d x\right.
$$

\subsubsection{Logistics and Distribution Risks}

Logistics and distribution of finished products involve management activities which reduce the time of storing finished products in the organization's stores to the minimum, do not cause any changes in product characteristics, and ensure security of transportation between the store and the sales network stores or the end recipient's store ${ }^{10}$.

The time spent by finished products in an organization's stores or in stores of an organization dealing with distribution, is a property characteristic to activities of management in the area of logistics and distribution. It can be measured by the finished product stock rotation ratio - $W_{r w g} /$ in case of stock rotation ratio for distribution network, $-W_{r d} I^{11}$. Besides the sales profitability ratio that is so important to the organization, the finished product stock rotation ratio includes additional information about the rate of the organization's added value growth.

Management activities concerning processes of storing and transporting finished products are mainly connected with the property-related risk; i.e. damage or theft, but also with the loss of the product's significant characteristics that determine the organization's competitive edge, such as significant characteristic of a new product in the market. Effects of risks in this area of activity will most probably force the management to make a decision to reduce the selling price or even to withdraw products from turnover. Such decisions reduce income from sales $\triangle P S$, causing further potential threat to financial liquidity.

Protection against consequences of property-related risks connected with activities in the sphere of logistics and distribution falls under the competence of the risk management system ${ }^{12}$. Except for prevention, the protection against such consequences as loss of property or decrease of its competitive value on the market resulting from processes of storage and distribution, should be assigned to instruments offered by risk carriers; and consequences of risks should be transferred to these institutions against payment.

The hypothetical profile of logistics and distribution risk is a vector $\boldsymbol{X}_{L i D}=\left(W_{r w g}, W_{r d}, \Delta P S\right)$.

Let $X_{1} \equiv W_{r w g}, \quad X_{2} \equiv W_{r d}, \quad X_{3} \equiv \Delta P S$ and let the function of probability distribution density be lognormal, with the assumption that random variables $X_{j}=x_{j}$ where $j=1,2,3$, take value from a certain closed interval $\left[a_{j}, b_{j}\right] \subset R^{+}$, then:

$$
f\left(x_{1}, x_{2}, x_{3}\right)=\frac{1}{(2 \pi)^{\frac{3}{2}} * \sqrt{|M|} * \prod_{l=1}^{3} x_{l}} \exp \left\{-\frac{1}{2} \sum_{g=1}^{3} \sum_{h=1}^{3} \gamma_{i j}\left(\ln x_{g}-\mu_{g}\right)\left(\ln x_{h}-\mu_{h}\right)\right\},
$$

\footnotetext{
${ }^{10}$ An organization's responsibility in transport is provided for in contracts. This risk can be taken over by the recipient/sales network/buyer.

${ }^{11}$ The ratio is computed as a quotient of the technical cost of the finished product to the average level of these products' stock. In the case of the ratio of finished products' rotation in the sales network, production cost is replaced by distribution cost. Dobija M. Rachunkowość zarządcza, Wydawnictwo Naukowe PWN, Warszawa 1996, p. 250.

${ }^{12}$ The department is usually a separate unit in the organizational structure.
} 
where: $M=\left(\begin{array}{ccc}\sigma_{1}^{2} & \eta_{12} & \eta_{13} \\ \eta_{21} & \sigma_{2}^{2} & \eta_{23} \\ \eta_{31} & \eta_{32} & \sigma_{3}^{2}\end{array}\right), \sigma_{l}^{2}$ stands for variance of random variable $X_{l}$ and $\eta_{g h}$ for covariance of variables $\left\{X_{g}, X_{h}\right\}$, while $\gamma_{g h}$ are elements of matrix $M^{-1}, g, h=1,2,3 .^{13}$

\subsubsection{Marketing and Sales Risks}

Marketing, understood as market-related activities, results from transformation of the producer's market into the recipient's market. It is an expression of difficulties with adjusting supply to demand. These tendencies are made even deeper by processes of restructuring that result from the progressing globalization and lead to increased competitiveness. Marketing is an attempt - a successful one - of seeking such form of functioning on the market that might determine the organization's competitive advantage. Thus, marketing should be considered as a significant component of the entire organization's management conception.

Marketing regarded as a management conception involves - due to the very nature of the management process - decisions concerning not only the market of products and services, but decisions concerning the labor market, capital, real property or intellectual property. Decisions are accompanied by risk, which is random by its nature; i.e. unpredictable. In many cases, this means that the organization's plans are not implemented as soon as they need to be; but in some extremely unfavorable circumstances, the plans need to be changed. Moreover, such broad marketing causes continuous pressure of environmental factors from the market of product, labor, capital, real property and intellectual property.

Active implementation of the organization's marketing policy is embedded, understandably, in the organization's strategic plans and it consequently acquires features characteristic to the main policy principles. Principles of the main policy are formulated for a period that is longer than one year. It is therefore required to outline specific policy principles which should be, obviously, in line with the main direction of the organization's policy.

The organization's main policy conception, in its application to marketing, assumes active presence of the organization on the product market first and then with additional focus on the labor, capital, real property and intellectual property market. Instrumental principles of marketing will be implemented, namely, in these areas. This means that the relations to be created in these markets need to meet the expectations relating to the marketing department work ${ }^{14}$.

Threats of implementation of the organization's main policy result from the uncertainty of the outcomes of two fundamental marketing conceptions presented in Chapter 4 of the study; i.e. " $4 \mathrm{P}$ " and " $4 \mathrm{C}$ ". Both conceptions constitute a unity, and the outcome of their joint implementation will determine the organization's success in the market.

The principles of the main policy should be considered in the context that is defined by the marketing theory as " $4 \mathrm{P}$ "; i.e. product, price, placement and promotion, and in terms of the " $4 \mathrm{C}$ " conception; i.e. consumer value, cost (the purchasing price), convenience of acquirement and communication. This method of formulating principles of the organization's main policy takes its interest into consideration, but also the buyer's interest by means of including the " $4 \mathrm{C}$ "conception.

${ }^{13}$ Definitions of production risks profile measures: the probability that risk profile components take value from the range $\left[a_{j}, b_{j}\right] \subset R^{+}$/where: $j=1,2,3 /$, profile expected value, variances of components $X_{j}$, covariances $\left\{X_{g}, X_{h}\right\} g \neq h$, probability, variances, covariances of conditional distributions are identical with those quoted for the logistics and procurement risk profile.

${ }^{14}$ They increase the number of the organization's business partners and strengthen its position in the market. 
Marketing tasks should be performed in a manner taking the related risks into account. This means that risks are connected with the organization's activities in the area of " $4 \mathrm{P}$ " and " $4 \mathrm{C}$ " conceptions and risk is allocated to area $P$ of decisions concerning: product, price, place and promotion, but also in area $C$, which involves consumer value, cost, convenience of acquirement and communication.

Risks in this area of the main policy will be related to the product range and identification of the target segments of the market. The product range should take the organization's resources into account and maximize its financial efficiency.

The risk profile is a random vector with two random variables showing the product range structure and the market segmentation. Both characteristics of the profile are qualitative variables, and this fact opens another problem as risk-defined measures are statistic, defined based on measurable variables. We are not making a mistake by stating that the correctness of decisions concerning the product range structure and the market segmentation will be confirmed by the sales growth dynamics $(\Delta S)$. Thus, product risk is a single-dimensional random vector $\boldsymbol{X}_{p}=$ $(\Delta S)$.

Let $X^{p} \equiv \triangle K P$ and besides, let the function of probability density distribution be lognormal, with the assumption that random variables $X^{p}=x_{p}$ take value from a certain closed interval of variability $[a, b] \subset R^{+}$, then:

a. The function of probability distribution density: $f(x)=\frac{1}{x \sigma \sqrt{2 \pi}} \exp \left\{-\frac{(\ln x-\mu)^{2}}{2 \sigma^{2}}\right.$,

where: $\sigma^{2}$ stands for variance of $X^{p}$ random variable and $\mu$ for average value of variable $X^{p} \cdot{ }^{15}$

The pricing policy has a direct influence on income and, at the same time, pricing policy assumptions should build an organization's advantageous position against its competitors. In this case, the product price is one of the policy elements. At the same time, one assumes that other equally significant assumptions are in use - that the product is "technically and technologically" up to date or its effect on the natural environment is neutral.

In the market economy, product price is a measure of balance between supply and demand. It measures the product's value, while on the other hand, it is an element of the competitive fight. Thus, price risk management will involve implementation of such pricing policy where the organization's products are competitive in the market when compared to those delivered by other business entities.

The price risk is a random vector with two random components by its definition: The organization's net profit $\left(Z_{n}\right)$ and rating on the market $(\mathrm{R})$; therefore $\boldsymbol{X}_{c}=\left(Z_{n}, R\right)$.

Let $X_{1} \equiv Z_{n}, \quad X_{2} \equiv R$ and besides let the function of probability distribution density be lognormal, with the assumption that random variables $X_{j}=x_{j}$ where $j=1,2$, take value from a certain closed interval of variability $\left[a_{j}, b_{j}\right] \subset R^{+}$, then:

a. The function of probability distribution density:

$$
f\left(x_{1}, x_{2}\right)=\frac{1}{(2 \pi) * \sqrt{|M|} * \prod_{l=1}^{2} x_{l}} \exp \left\{-\frac{1}{2} \sum_{g=1}^{2} \sum_{h=1}^{2} \gamma_{g h}\left(\ln x_{g}-\mu_{g}\right)\left(\ln x_{h}-\mu_{h}\right)\right\},
$$

\footnotetext{
${ }^{15}$ Definitions of the production risk profile measures: the probability that risk profile components take value from the range $[a, b] \subset R^{+}$, profile expected value, variance of component $X^{p}$, are identical with those quoted for the production risk profile.
} 
where: $M=\left(\begin{array}{ll}\sigma_{1}^{2} & \eta_{12} \\ \eta_{21} & \sigma_{2}^{2}\end{array}\right), \sigma_{l}^{2}$ stands for variance of $X_{l}$ random variable and $\eta_{i j}$ for covariance of $\left\{X_{1}, X_{2}\right\}$, variables, while $\gamma_{g h}$ represent elements of matrix $M^{-1}, g, h=1,2$.

b. The probability of events that random variables $X_{j}$ take value $x_{j}$ from the range:

$$
P\left(a_{1} \leq x_{1} \leq b_{1}, a_{2} \leq x_{2} \leq b_{2}\right)=\int_{a_{1}}^{b_{1}} \int_{a_{2}}^{b_{2}} f\left(x_{1}, x_{2}\right) d x_{1} d x_{2} .
$$

c. Expected value of the logistics and procurement risk profile $E(X)=\left(E\left(X_{1}\right), E\left(X_{2}\right)\right)$, where vector components equal respectively: $E\left(X_{l}\right)=\int_{a_{l}}^{b_{l}} x_{l} f\left(x_{1}, x_{2}\right) d x_{l}$, where $l=1,2$.

d. $\quad$ Variance of the logistics and procurement risk profile $\left\{X_{l}\right\}$, equals:

$$
\operatorname{Var}\left(X_{l}\right)=\int_{a_{l}}^{b_{l}}\left[x_{l}-E\left(X_{l}\right)\right]^{2} f\left(x_{1}, x_{2}\right) d x_{l}, \text { gdzie } l=1,2 .
$$

e. Covariance of the logistics and procurement risk profile $\left\{X_{1}, X_{2}\right\}$, equals:

$$
\operatorname{Cov}\left(X_{1}, X_{2}\right)=\int_{a_{1}}^{b_{1}} \int_{a_{2}}^{b_{2}}\left[x_{1}-E\left(X_{1}\right)\right]\left[x_{2}-E\left(X_{2}\right)\right] f\left(x_{1}, x_{2}\right) d x_{1} d x_{2} .
$$

f. The function of conditional probability distribution density, with the assumption that for any component $\left\{X_{j}\right\}$, where $j=1,2$, the variable takes constant value $X_{j}=x$, while variables $\left\{X_{l}\right\}$ may take value from the range $\left[a_{l}, b_{l}\right] \subset R^{+}$, where $l=1,2 \wedge l \neq j$; equals by definition:

$$
P\left(a_{l} \leq x_{l} \leq b_{l} \mid X_{j}=x\right)=\int_{a_{l}}^{b_{l}} x_{l} \frac{f\left(x_{1}, x_{2}\right)}{f\left(x_{j}\right)} d x_{l} \text {, where: } l=1,2 \quad l \neq j .
$$

$\mathrm{f}_{1}$. Conditional expected value of the logistics and procurement risk profile is a random vector, if one of the components of the profile is constant $X_{j}=x$, while the remaining variables $\left\{X_{l}\right\}$ may take value from the range $\left[a_{l}, b_{l}\right] \subset R^{+}$, where $l=1,2 \wedge l \neq j$, equals by definition:

$$
E\left(E\left(X_{1} \mid X_{2}=x_{2}\right), E\left(X_{2} \mid X_{1}=x_{1}\right)\right) \text {, where } E\left(X_{l} \mid X_{j}=x\right)=\int_{a_{l}}^{b_{l}} x_{l} \frac{f\left(x_{1}, x_{2}\right)}{f\left(x_{j}\right)} d x_{l} \text {. }
$$

$\mathrm{f}_{2}$. Conditional variance of the logistics and procurement risk profile characteristics, if one of the profile components $X_{j}=x$ takes constant value, while the remaining characteristics $\left\{X_{l}\right\}$ may take any value from the range $\left[a_{l}, b_{l}\right] \subset R^{+}$, where $l=1,2 \wedge l \neq j$ equals by definition:

$$
\operatorname{Var}\left(X_{l} \mid X_{j}=x\right)=\int_{a_{l}}^{b_{l}}\left[x_{l}-E\left(X_{l} \mid X_{j}=x\right)\right]^{2} f\left(x_{1}, x_{2}, x_{3}\right) d x_{l} .
$$

Distrubution should be characterised by effectiveness understood as a perfrect correlation between dem and and logistic potential. Logistic potential will be evaluated in terms of the time of delivery and assumptions of the main policy aimed at such regular solutions which, while changing in line with logistic circumstances, will always 
accept the criterion of minimizing the duration of the longest delivery in the logistic network ${ }^{16}$. Delivery duration is correlated with the cost - the cost of distribution in this case.

The distribution-related part of the main policy should define the assumptions concerning payment for the product introduced to the sales network. These principles should specify forms of payment; in the case of product batch delivery, payment in cash or deferred payment should be indicated.

Main policy assumptions for the area of distribution enable one to notice that the distribution risk profile is defined by two characteristics: cost of distribution and whether the recipients' pay their liabilities in due time.

Thus, distribution risk is a random vector with two random components: distribution cost $K_{d}$ and the other "explains" the organization's accounts receivable timeliness. Its measure is identical with the accounts receivable rotation ratio $W_{r n}$; therefore, $\boldsymbol{X}_{\boldsymbol{d}}=\left(K_{d}, W_{r n}\right)$.

Let $X_{1} \equiv K_{d}, \quad X_{2} \equiv W_{r n}$ and besides let the function of probability distribution density be lognormal, with the assumption that random variables $X_{j}=x_{j}$ where $j=1,2$, Take value from a certain closed interval of variability $\left[a_{j}, b_{j}\right] \subset R^{+}$, then the probability distribution density function:

$$
f\left(x_{1}, x_{2}\right)=\frac{1}{(2 \pi) * \sqrt{|M|} * \prod_{l=1}^{2} x_{l}} \exp \left\{-\frac{1}{2} \sum_{g=1}^{2} \sum_{h=1}^{2} \gamma_{g h}\left(\ln x_{g}-\mu_{g}\right)\left(\ln x_{h}-\mu_{h}\right)\right\}
$$

where: $M=\left(\begin{array}{ll}\sigma_{1}^{2} & \eta_{12} \\ \eta_{21} & \sigma_{2}^{2}\end{array}\right), \sigma_{l}^{2}$ stands for variance of $X_{l} / l=1,2 /$, random variable and $\eta_{g h}$ for covariance of variables $\left\{X_{g}, X_{h}\right\}, g, h=1,2 .^{17}$

Risks of promotion, considered in terms of the organization's main policy, are determined by advertising with other channels of information about the products and producer. These other channels include sponsoring, sales promotion and public relations. Promotion-related activities - or more precisely, the effects of these activities should be measured; but how? Irrespective of the information channel, instruments of promotion generate costs which, when compared against financial effects, determine the return on promotion outlays. There is no doubt that the growth of revenue from sales against the outlay is a "good" measure of return, indicating the effectiveness of promotion.

Besides the relation that defines promotion efficiency, the risk of promotion is determined by AIDASR, with the special significance of the last element - repetition - in influencing the potential client. This means that the set of promotion risks profile characteristics identified thus far is insufficient; it needs to be supplemented with data about the frequency of the given client's purchases.

\footnotetext{
${ }^{16}$ Irrespective of logistic solutions, deliveries may be performed by the producing organization or by an external entity providing logistic services. The problem remains invariably the same: optimization of delivery duration involving minimalization of delivery costs. Irrespective of the solution, this problem is one of classical transport-related issues which have been solved by Ford and Fulkerson.

${ }^{17}$ Definition of the distribution risk profile measures probability that risk profile components take value from the range $\left[a_{j}, b_{j}\right] \subset R^{+} /$where: $j=1,2 /$, profile expected value, variance of components $X_{j}$, covariance $\left\{X_{l}, X_{h}\right\} \quad l \neq h$, probability, variance, covariance of conditional distribution are identical with those quoted for the price risk profile.
} 
The risk of promotion is a random vector with two random components: the ratio of promotion cost to the organization's revenue from sales growth $W=\frac{k_{p}}{\Delta p s}$ and $T_{z}$ - a variable informing the frequency of the given client's purchasing. $\boldsymbol{X}_{p r}=\left(W, T_{z}\right)$.

Let $X_{1} \equiv W, \quad X_{2} \equiv T_{z}$ and besides let the function of probability distribution density be lognormal, with the assumption that random variables $X_{j}=x_{j}$ where $j=1,2$, Take value from a certain closed interval of variability $\left[a_{j}, b_{j}\right] \subset R^{+}$, the function of probability distribution density:

$$
f\left(x_{1}, x_{2}\right)=\frac{1}{(2 \pi) * \sqrt{|M|} * \prod_{l=1}^{2} x_{l}} \exp \left\{-\frac{1}{2} \sum_{g=1}^{2} \sum_{h=1}^{2} \gamma_{g h}\left(\ln x_{g}-\mu_{g}\right)\left(\ln x_{h}-\mu_{h}\right)\right\},
$$

where: $M=\left(\begin{array}{ll}\sigma_{1}^{2} & \eta_{12} \\ \eta_{21} & \sigma_{2}^{2}\end{array}\right), \sigma_{l}^{2}$ stands for variance of $X_{l} / l=1,2 /$, random variable and $\eta_{g h}$ for covariance of variables $\left\{X_{g}, X_{h}\right\}, g, h=1,2 .^{18}$

\subsubsection{Risks of Servicing}

Servicing is the last link in the organization's basic value chain, linking the organization to the buyer. The quality of these relations is particularly important for the organization. It includes important information about the product, enables the organization to compare its products with those offered by competitors, and it gives a trustworthy basis for evaluation of the servicing quality.

An organization's activities in the area of servicing include services provided before the product is sold as well as afterward, in the guarantee and warranty period. Servicing activities before sales are intended to emphasize product characteristics and to benchmark it against products offered by the competition in a manner that will persuade the potential client to select and buy the organization's product.

An organization's selling activities, whether performed by the organization's distribution network or by a network managed by an independent entity, are assessed by buyers. This assessment is measured by dynamics of sales which is approximated with a high degree of probability by changes in the ratio of product sales to production volume at some specific point in time: $W_{s / p}$.

After-sales servicing may, and should, include product installation if it is required or training in operation and maintenance. Risks of after-sales servicing activities are revealed by product return, repair or replacement with a new product. In such cases, the organization's activities should reduce such consequences of risk as dissemination and establishment of the buyer's opinion of the product, which is a difficult task. The organization takes less risk when it analyzes the motivation behind the buyer's decision. This may even mean the need to call on the buyers to return the purchased products in order to repair them, replace with new items, or return the money. This depends on causes of the product return and may result from technical defects of design, faulty installation, insufficient or incomplete instructions, or training.

In extreme cases, consequences of risks in the area of product technical quality may even lead to an organization's bankruptcy. If the scale of sales is large, buyers' claims may cause irreversible loss of liquidity.

\footnotetext{
${ }^{18}$ Measures of the promotion risk profile, with the markings accepted here, remain the same as definitions of the price risk profile measures.
} 
Consequences of risks of faulty installation or insufficient instructions or training can be eliminated, if only they are noticed.

Risks of after-sales servicing should be measured by means of ratios defining the relation between sales value and value of returned products with irremovable defects - $W_{s / s n}$ and defining the relation between sales value and value of products with removable defects - $W_{s / s u}$. Servicing also deals with cases resulting from users' faults caused by their inattention or resulting from faulty instructions and a training program. One may assume that the number of defects is inversely proportional to outlays in training program preparation - $K_{s}$. A persuasive informational content is included in the relation between outlay of training and production costs - $W_{n s / k p}$.

Identification of risk components enables one to define the servicing risk profile - it is a random vector $\boldsymbol{X}_{s}=\left(W_{s / p}, W_{s / s n}, W_{s / s u}, K_{s}, W_{n s / k p}\right)$.

Let $X_{1} \equiv W_{s / p}, \quad X_{2} \equiv W_{s / s n}, \quad X_{3} \equiv W_{s / s u}, \quad X_{4}=K_{s}, \quad X_{5}=W_{n s / k p}$ and besides let the function of probability distribution density be lognormal with the assumption that random variables $X_{j}=x_{j}$ where $\quad j=$ $1,2,3,4,5$, take value from a certain closed interval of variability $\left[a_{j}, b_{j}\right] \subset R^{+}$, then:

a. The function of probability distribution density:

$$
f\left(x_{1}, x_{2}, x_{3}, x_{4}, x_{5}\right)=\frac{1}{(2 \pi)^{\frac{5}{2}} * \sqrt{|M|} * \prod_{l=1}^{5} x_{l}} \exp \left\{-\frac{1}{2} \sum_{g=1}^{5} \sum_{h=1}^{5} \gamma_{g h}\left(\ln x_{g}-\mu_{g}\right)\left(\ln x_{h}-\mu_{h}\right)\right\},
$$

where: $M=\left(\begin{array}{ccccc}\sigma_{1}^{2} & \eta_{12} & \eta_{13} & \eta_{14} & \eta_{15} \\ \eta_{21} & \sigma_{2}^{2} & \eta_{23} & \eta_{24} & \eta_{25} \\ \eta_{31} & \eta_{32} & \sigma_{3}^{2} & \eta_{34} & \eta_{35} \\ \eta_{41} & \eta_{42} & \eta_{43} & \sigma_{4}^{2} & \eta_{45} \\ \eta_{51} & \eta_{52} & \eta_{53} & \eta_{54} & \sigma_{5}^{2}\end{array}\right), \sigma_{l}^{2}$ stands for variance of random variable $X_{l}, l=1,2, \ldots, 5$ and

$\eta_{g h}$ for covariance of variables $\left\{X_{g}, X_{h}\right\}$, while $\gamma_{g h}$ represent elements of matrix $M^{-1}, g, h=1,2,3,4,5$.

Let $\boldsymbol{A B}=\left[a_{1}, b_{1}\right] \times\left[a_{2}, b_{2}\right] \times\left[a_{3}, b_{3}\right] \times\left[a_{4}, b_{4}\right] \times\left[a_{5}, b_{5}\right]$ be a Cartesian product of sets $\left[a_{j}, b_{j}\right] \subset R^{+}$, where $\quad j=$ $1,2,3,4,5$ and $f(x) \equiv f\left(x_{1}, x_{2}, x_{3}, x_{4}, x_{5}\right), d x=d x_{1} d x_{2} d x_{3} d x_{4} d x_{5}$.

b. The probability of events that random variable $\boldsymbol{X}$ takes value $\boldsymbol{x}$ from set $\boldsymbol{A B}$ :

$$
P(A \leq x \leq B)=\int_{A B} f(x) d x^{19}
$$

\footnotetext{
${ }^{19}$ Formulas $P(A \leq x \leq B)$ and $\int_{A B} f(x) d x$ are simplified to some degree, as a result of scarce space, as:

$\int_{A B} f(x) d x=\int_{a_{1}}^{b_{1}} \int_{a_{2}}^{b_{2}} \int_{a_{3}}^{b_{3}} \int_{a_{4}}^{b_{4}} \int_{a_{5}}^{b_{5}} f\left(x_{1}, x_{2}, x_{3}, x_{4}, x_{5}\right) d x_{1} d x_{2} d x_{3} d x_{4} d x_{5}$.
} 
c. Servicing risk profile expected value $E(X)=\left(E\left(X_{1}\right), E\left(X_{2}\right), E\left(X_{3}\right), E\left(X_{4}\right), E\left(X_{5}\right)\right)$, where vector components equal respectively: $E\left(X_{l}\right)=\int_{a_{l}}^{b_{l}} x_{l} f\left(x_{1}, x_{2}, x_{3}, x_{4}, x_{5}\right) d x_{l}, l=1, \ldots, 5$.

d. Variances of logistics and procurement risk profile characteristics $\left\{X_{l}\right\}$, equal:

$$
\operatorname{Var}\left(X_{l}\right)=\int_{a_{l}}^{b_{l}}\left[x_{l}-E\left(X_{l}\right)\right]^{2} f\left(x_{1}, x_{2}, x_{3}, x_{4}, x_{5}\right) d x_{l} \text {, where } l=1,2,3,4,5 .
$$

e. Covariance of the logistics and procurement risk profile characteristics $\left\{X_{g}, X_{h}\right\}$, equal:

$$
\operatorname{Cov}\left(X_{g}, X_{h}\right)=\int_{a_{g}}^{b_{g} b_{h}} \int_{h}\left[x_{g}-E\left(X_{g}\right)\right]\left[x_{h}-E\left(X_{h}\right)\right] f\left(x_{1}, x_{2}, x_{3}, x_{4}, x_{5}\right) d x_{g} d x_{h},
$$

gdzie: $g, h=1,2,3,4,5 \wedge g \neq h$.

f. The function of conditional probability distribution density, with the assumption that for any component $\left\{X_{j}\right\}$, where $j=1,2,3,4,5$ the variable takes constant value $X_{j}=x$, while variables

$\left\{X_{1^{p}}, X_{2^{p}}, X_{3^{p}}, X_{4^{p}}\right\} \subset\left\{X_{1}, X_{2}, X_{3}, X_{4}, X_{5}\right\} \wedge\left(1^{p}, 2^{p}, 3^{p}, 4^{p}\right) \subset(1,2,3,4,5)$ may take value from the $P=\left[a_{1^{p}}, b_{1^{p}}\right] \times\left[a_{2^{p}}, b_{2^{p}}\right] \times\left[a_{3^{p}}, b_{3^{p}}\right] \times\left[a_{4^{p}}, b_{4^{p}}\right] \subset R^{4}$ equals by definition:

$$
P\left(x_{1^{p}}, x_{2^{p}}, x_{3^{p}}, x_{4^{p}} \in P \mid X_{j}=x\right)=\int_{P} \frac{f\left(x_{1}, x_{2}, x_{3}, x_{4}, x_{5}\right)}{f\left(x_{j}\right)} d x_{1^{p}}, d x_{2^{p}}, d x_{3^{p}}, d x_{4^{p}} .
$$

$\mathrm{f}_{1}$. Conditional expected value of the logistics and procurement risk profile is a random vector. If one of the profile components is constant $X_{j}=x$, while the remaining variables

$\left\{X_{1^{p}}, X_{2^{p}}, X_{3^{p}}, X_{4^{p}}\right\} \subset\left\{X_{1}, X_{2}, X_{3}, X_{4}, X_{5}\right\} \wedge\left(1^{p}, 2^{p}, 3^{p}, 4^{p}\right) \subset(1,2,3,4,5)$ may take values from the $\left[a_{1^{p}}, b_{1^{p}}\right] x\left[a_{2^{p}}, b_{2^{p}}\right] x\left[a_{3^{p}}, b_{3^{p}}\right] x\left[a_{4^{p}}, b_{4^{p}}\right] \subset R^{4}$, equals by definition:

$$
E\left(E\left(X_{1^{p}} \mid X_{j}=x\right), E\left(X_{2^{p}} \mid X_{j}=x\right), E\left(X_{3^{p}} \mid X_{j}=x\right), E\left(X_{4^{p}} \mid X_{j}=x\right)\right),
$$

gdzie $E\left(X_{l^{p}} \mid X_{j}=x\right)=\int_{l_{l^{p}}}^{b_{l^{p}}} x_{l^{p}} \frac{f\left(x_{1}, x_{2}, x_{3}, x_{4}, x_{5}\right)}{f\left(x_{j}\right)} d x_{l^{p}}$, gdzie $l^{p}=1,2,3,4,5 \wedge l^{p} \neq j$.

$\mathrm{f}_{2}$. Conditional variance of the logistics and procurement risk profile characteristics, if one of the profile components $X_{j}=x$ takes constant value, while the remaining characteristics $\left\{X_{l}\right\}$ may take any value from the range $\left[a_{l}, b_{l}\right] \subset R^{+}$, where $l=1,2,3,4,5 \wedge l \neq j$, equals by definition:

$$
\operatorname{Var}\left(X_{l} \mid X_{j}=x\right)=\int_{a_{l}}^{b_{l}}\left[x_{l}-E\left(X_{l} \mid X_{j}=x\right)\right]^{2} f\left(x_{1}, x_{2}, x_{3}, x_{4}, x_{5}\right) d x_{l} .
$$

$\mathrm{f}_{3}$. Conditional covariance of characteristics $\left\{X_{g}, X_{h}\right\}$ of the logistics and procurement risk profile, on the condition that $X_{j}=x ; j=1,2,3,4,5$, equal: 
$\operatorname{Cov}\left(\left(X_{g}, X_{h}\right) \mid\left(X_{j}=x\right)\right)=\int_{a_{g}}^{b_{g} b_{h}}\left[x_{g}-E\left(X_{g} \mid\left(X_{j}=x\right)\right)\right]\left[x_{h}-E\left(X_{h} \mid\left(X_{j}=x\right)\right)\right] f\left(x_{1}, x_{2}, x_{3}, x_{4}, x_{5}\right) d x_{g} d x_{h}$

where: $g, h=1,2,3,4,5 \wedge(g \neq h, g \neq j, h \neq j)$.

\section{CONCLUSION}

Two theses have been set forth in this paper: 1) the possibility of identifying risks of the organization's basic value chain and 2) the possibility of measuring identified risks. Have they been proven convincingly? The answer is yes. This belief results from the fact of using reliable methods of description and measurement formulated by mathematical statistics. The axiom of the risk model identity with the random vector is the central point of the proof. This transfers the solution of the problem to the space of random vectors together with all consequences of this step. In terms of theses set forth here, there is a possibility of using the instrumental potential of mathematical statistics for measuring changes in the position of the random vector, the management activities risk. Changes in the random vector position in the vector space are caused by changes in its components. Thus, if instruments of mathematical statistics record such changes, it means that noticeable changes occur in the risk level.

The theoretical reasoning has been supported by an analysis solving the problems of identifying and measuring risks of the organization's basic value chain. Risks of the basic chain activities have been identified, properties of activities constituted the foundation of the process of the basic chain risk components identification, and finally, the stage of gathering proof of the thesis about the possibility of measuring the value chain risks took place.

The set of measures particularly includes important elements; i.e. measures related to conditional events that describe the activities of the organization's management that are frequent in practice when some characteristics of risks are showing a noticeable invariability. Conditional measures of events enable one to formulate important questions about changes of the risk measures if one of its characteristics remains invariably constant. This property of the set of risk characteristics and its measures may constitute a foundation of simulation processes in the organization's risk management.

\section{AUTHOR INFORMATION}

Jerzy Zemke graduated at the Nicolaus Copernicus University in Torun, where he completed his Master Thesis in Mathematics. He obtained his Ph.D. degree in Economics at University of Gdansk. He lectures at the Faculty of Management of the University of Gdansk in mathematics, econometrics, operation research, and risk in economic organizations. During the period 2005 - 2008 his research interests focused on enterprises' management under risk and especially on formalization of the risk space definition, the risk itself and risk measurement methods. The results have been published in the monograph 'Risks in economic organization management' (edited by the University of Gdansk, April 2009). Additionally to his academic assignments, he collaborates with financial institutions, banks and insurance companies. He is a licensed insurance and reinsurance broker.

\section{REFERENCES}

1. Barney J.B., Gaining and Sustaining Competitive Advantage, Prentice Hall, Upper Sadle River, NJ, 2002,

2. Bartoszewicz J., Wyktady ze statystyki ekonomicznej, PWN, Warszawa 1989,

3. Duliniec E., Badania marketingowe w zarzadzaniu przedsiębiorstwem, PWN, Warszawa 1994,

4. Feller W., Wstęp do rachunku prawdopodobieństwa, PWN, Warszawa vol. I 1977, vol. II 1978,

5. Gołębiowski T., Zarządzanie strategiczne. Planowanie i kontrola, Difin Warszawa 2001,

6. Haberberg A., Rieple A., The Strategic Management of Organization, Financial Times - Prentice Hall, Harlow 2001,

7. Kotler Ph. Marketing. Analiza, planowanie, wdrażanie i kontrola. Gebethner i S-ka, Warszawa 1994,

8. $\quad$ Lynch R., Corporate Strategy, Pitman Publishing, London 1997,

9. Niestrój R., Zarzadzanie marketingiem, aspekty strategiczne, Wydawnictwo Naukowe PWN, Warszawa Kraków 1998, 
10. Pawłowski Z., Wstęp do statystyki matematycznej, PWN, Warszawa 1969,

11. Porter M.E., Strategia konkurencji. Metody analizy sektorów i konkurentów, PWE Warszawa 1994,

12. Rokita J., Zarządzanie strategiczne. Tworzenie i utrzymanie przewagi strategicznej, PWE Warszawa 2005

13. Podstawy marketingu, Collective work edited by Altkorn J., Instytut Marketingu, Kraków 2000.

\section{NOTES}

